\title{
Differential proteomic analysis of respiratory failure in peripheral blood mononuclear cells using iTRAQ technology
}

\author{
GUOPING SUN ${ }^{1 *}$, CUIHUI CAO ${ }^{1 *}$, WENBIAO CHEN $^{2}$, YANG ZHANG $^{1}$ and YONG DAI ${ }^{2}$ \\ ${ }^{1}$ Central Laboratory of Pingshan New District People's Hospital of Shenzhen; ${ }^{2}$ Clinical Medical Research Center, \\ The Second Clinical Medical College of Jinan University, Shenzhen People's Hospital, \\ Shenzhen, Guangdong 518020, P.R. China
}

Received November 24, 2015; Accepted March 8, 2016

DOI: $10.3892 /$ br.2016.633

\begin{abstract}
Respiratory failure (RF) is a state in which the respiratory system fails by its gas exchange functions. Failure of the lung, which is caused by all types of lung diseases, leads to hypoxaemia with type I respiratory failure. Failure of the pump leads to hypercapnia or type II respiratory failure. Using isobaric tags for relative and absolute quantification (iTRAQ) technology to identify and quantify the total proteins in peripheral blood mononuclear cells (PBMCs) of RF patients and identify the differentially expressed proteome. The present study analyzed the total proteins in the PBMCs of RF patients and healthy controls using the eight-plex iTRAQ added with strong cation-exchange chromatography and liquid chromatography coupled with tandem mass spectrometry. The differentially expressed proteins were identified by MASCOT. A total of 4,795 differentially expressed proteins were identified, and 403 proteins were upregulated and 421 were downregulated. Among them, 4 proteins were significantly differentially expressed, which were upregulated KIAA1520 protein and $\gamma$ fibrinogen type B (AA at 202) and downregulated chain $\mathrm{A}$, crystal structure of recombinant human platelet factor 4 and myosin regulatory light polypeptide 9. iTRAQ technology is suitable for identifying and quantifying the proteome in the PBMCs of RF patients. The differentially expressed proteins of RF patients have been identified in the present study, and further research of the molecular mechanism of the differentially expressed proteins is required to clarify the pathogenesis and identify novel biomarkers of RF.
\end{abstract}

Correspondence to: Professor Yong Dai, Clinical Medical Research Center, The Second Clinical Medical College of Jinan University, Shenzhen People's Hospital, Shenzhen, Guangdong 518020, P.R. China

E-mail: daiyong2222@gmail.com

*Contributed equally

Key words: diagnostic techniques, respiratory system, proteomics, tandem mass spectrometry

\section{Introduction}

Respiratory failure (RF) is a state in which the respiratory system fails by its gas exchange functions. Usually, $R F$ is defined by an arterial oxygen tension $\left(\mathrm{PaO}_{2}\right)$ of $<8.0 \mathrm{kPa}$ $(60 \mathrm{mmHg})$ and an arterial carbon dioxide tension $\left(\mathrm{PaCO}_{2}\right)$ of $>6.0 \mathrm{kPa}(45 \mathrm{mmHg})$. These cut-off values of respiratory failure serve as a general guide and are coupled with the history and clinical assessment of RF patients (1). The respiratory system includes the lung and the pump that ventilates the lungs (2). Failure of the lung, which is caused by all types of lung diseases leads to hypoxemia with type I respiratory failure. Failure of the pump leads to hypercapnia or type II respiratory failure (3).

In the RF research, one of the main aims is to identify biomarkers for a better understanding of RF pathogenesis and improving diagnosis. Aberrant functions of the lymphocytic regulatory pathway were widely associated with the pathological mechanism of certain diseases and peripheral blood mononuclear cells (PBMCs) were used as feasible samples in these studies (4). In the past several years, the developments in proteomics research of numerous rheumatic diseases have been reported (4-6). Isobaric tags for relative and absolute quantification (iTRAQ) technology has increasingly been used in biomarker research for numerous diseases (7-10). However, to the best of our knowledge, there is no previous study of iTRAQ technology applied to PBMCs of RF. If the differentially expressed proteins in the PBMCs of RF patients could be identified using proteomic analysis, then these proteins could serve as a basis for the development of proteomics research of RF.

iTRAQ reagents comprise three parts: A peptide reactive group, a reporter group and a molecular mass balance. Different protein samples are noted with a corresponding iTRAQ mass group (i.e., 113, 114 and $115 \mathrm{Da}$ ) which could be quantified. The proteomics workflow comprises two parts: 2-dimensional orthogonal resolution of peptides by strong cation exchange (SCX) and high-performance liquid chromatography (HPLC). Subsequently, the fractions were analyzed through tandem mass spectrometry (MS/MS). The sequence information (from peptide fragments) and relative quantification (from reporter group ions) are provided from the resultant mass spectra. In the present study, the total proteins in the PBMCs of RF patients were analyzed through iTRAQ 
technology. Further research of the molecular mechanism of the proteins can better clarify the pathogenesis and identify novel biomarkers of RF.

\section{Materials and methods}

Main reagents. Triton X-100 and a Strata-X 33u Polymeric Reversed Phase column were separately purchased from Amersham Biosciences (Waukesha, WI, USA) and Phenomenex (Los Angeles, CA, USA). The Bicinchoninic Acid (BCA) Protein Assay Reagent kit and triethylammonium bicarbonate buffer were respectively acquired from Pierce (Thermo Fisher Scientific, Inc., Rockford, IL, USA) and Sigma-Aldrich (Supelco, Bellefonte, Pennsylvania, USA). ZipTip Pipette tips and Milli-Q water were obtained from Millipore (Billerica, MA, USA). The iTRAQ Reagent-8Plex Multiplex kit and Trypsin Gold, mass spectrometry grade were respectively acquired from Applied Biosystems (Carlsbad, CA, USA) and Promega (Madison, WI, USA). All the other reagents were obtained from commercial sources.

Patients and healthy controls. The samples included 5 patients and 5 healthy controls. The participants were from Shenzhen People's Hospital (Shenzhen, China), between April and October 2013. The 5 patients, who were diagnosed as type IIRF, included 4 women and 1 man with an average age of 35.22 years; range, $28-45$ years. The age and gender of the 5 healthy controls were matched with the 5 patients. The diagnosis of RF was confirmed by pathological diagnosis and clinical evidence.

The healthy controls were confirmed to have no clinical evidence of RF. All the subjects provided informed consents. The study was approved by the regional ethics committee and abided by the Helsinki Declaration.

PBMC isolation, protein extraction and quantitation. One 5 -ml fasting venous blood sample from each participant was collected into the corresponding heparinize vacutainers. According to the manufacturer's protocol (Cedarlane Laboratories, Burlington, ON, Canada), PBMCs were isolated with lymphocyte-H medium. The concentration of total protein for PBMCs, which was extracted, was measured with the BCA protein assay kit. The protein samples were kept at $-80^{\circ} \mathrm{C}$ for further analysis.

iTRAQ labeling and SCX fractionation. Firstly, a ratio of protein:trypsin $=30: 1$ was used to generate the Trypsin Gold. Subsequently, the Trypsin Gold was used to digest the equal amounts $(100 \mu \mathrm{g})$ of protein in the PBMCs of the samples at $37^{\circ} \mathrm{C}$ for $16 \mathrm{~h}$. Following the digestion, peptides were dried through vacuum centrifugation. Following the manufacturer's protocol, peptides were reconstituted in 0.5 M TEAB and processed for 8-plex iTRAQ reagent. In brief, samples were thawed and reconstituted in one unit of iTRAQ reagent in $24 \mu 1$ isopropanol. Samples were labeled with the iTRAQ tags (samples 114 and 115). The peptides labeled with the isobaric tags were incubated with them at room temperature for $2 \mathrm{~h}$. Subsequently the labeled peptide mixtures were pooled and dried by vacuum centrifugation.

SCX chromatography was performed through an LC-20AB HPLC Pump system (Shimadzu, Kyoto, Japan).
The iTRAQ-labeled peptide mixtures were reconstituted with $4 \mathrm{ml}$ of buffer A [25 mM NaH${ }_{2} \mathrm{PO}_{4}$ in $25 \%$ acetonitrile $(\mathrm{ACN})(\mathrm{pH} 2.7)]$. Subsequently, the iTRAQ-labeled peptide mixtures were loaded onto a 4.6x250 mm Ultremex SCX column containing $5-\mu \mathrm{m}$ particles (Phenomenex). After the loading process, the peptides were eluted at a flow rate of $1 \mathrm{ml} / \mathrm{min}$ with a gradient of $100 \%$ buffer A for $10 \mathrm{~min}$. Secondly, the peptides were eluted at a flow rate of $1 \mathrm{ml} / \mathrm{min}$ with a gradient of $5-60 \%$ buffer B [ $25 \mathrm{mM} \mathrm{NaH}_{2} \mathrm{PO}_{4}, 1 \mathrm{M}$ $\mathrm{KCl}$ in $25 \% \mathrm{ACN}$ (pH 2.7)] for $27 \mathrm{~min}$. Thirdly, the peptides were eluted at a flow rate of $1 \mathrm{ml} / \mathrm{min}$ with a gradient of $60-100 \%$ buffer B for 1 min. Before equilibrating with buffer $\mathrm{A}$ for $10 \mathrm{~min}$ prior to the next injection, the system was maintained at $100 \%$ buffer B for $1 \mathrm{~min}$. The elution was analyzed through measuring the absorbance at $214 \mathrm{~nm}$, and collecting the fractions every $1 \mathrm{~min}$. Following this, the eluted peptides were pooled into 20 fractions and the eluted peptides were desalted with a Strata X C18 column (Phenomenex) and vacuum-dried.

LC-ESI-MS/MS analysis based on Q-Exactive. Each fraction was resuspended in buffer A [2\% ACN, $0.1 \%$ formic acid (FA)] and centrifuged at 20,000 x g for $10 \mathrm{~min}$. The final concentration of the peptide was $\sim 0.5 \mu \mathrm{g} / \mu \mathrm{l}$. In total, $10 \mu 1$ supernatant was loaded on an LC-20AD nano-HPLC (Shimadzu) through the autosampler onto a 2-cm C18 trap column. The peptides were eluted onto a $10-\mathrm{cm}$ analytical C18 column (inner diameter $75 \mu \mathrm{m}$ ) packed in-house. The samples were loaded at $8 \mu \mathrm{l} / \mathrm{min}$ for $4 \mathrm{~min}$. The $44 \mathrm{~min}$ gradient was run at $300 \mathrm{nl} / \mathrm{min}$ from 2 to $35 \% \mathrm{~B}(98 \% \mathrm{ACN}$, $0.1 \%$ FA), followed by a 2 -min linear gradient to $80 \%$, and maintained at $80 \%$ B for $4 \mathrm{~min}$, prior to reverting to $5 \%$ for $1 \mathrm{~min}$.

The peptides were subjected to nanoelectrospray ionization through MS/MS in an Q-Exactive (Thermo Fisher Scientific, San Jose, CA, USA), which was online to the HPLC and detected the intact peptides in the orbitrap at a resolution of 70,000. The peptides for MS/MS were selected through high-energy collision dissociation. A data-dependent procedure was used, which alternated between one MS scan through $15 \mathrm{MS} / \mathrm{MS}$ scans. The data-dependent procedure was applied to the 15 most abundant precursor ions above a threshold ion count of 20,000 in the MS survey scan with a following dynamic exclusion duration of $15 \mathrm{sec}$. The operating electrospray voltage was $1.6 \mathrm{kV}$. Automatic gain control (AGC) was used to optimize the spectra generated through the orbitrap. The AGC target for a full MS was $3 \mathrm{e} 6$. The $\mathrm{m} / \mathrm{z}$ scan range was 350-2,000 Da for the MS scans.

Data analysis. MASCOT version 2.3.02 (Matrix Science, Ltd., London, UK) was used to analyze the identification and quantification of the proteins. The peptide sequences were searched in the nonredundant NCBI database. The search criteria were set to permit a maximum of 1 missed cleavage. Certain peptide modifications were permitted: For example, Gln->pyro-Glu, iTRAQ 8plex, Phospho. The values supplied with the Applied Biosystems reagents were used to carry out automatic isotope correction through both software packages. Subsequently, Gene Ontology (GO) (http://www. geneontology.org) was used to elucidate the molecular 
Table I. Identification results.

\begin{tabular}{|c|c|c|c|c|c|c|}
\hline Source & Total spectra & Spectra & Unique spectra & Peptide & Unique peptide & Protein \\
\hline Homosapien & 342,324 & 81,690 & 67,339 & 21,788 & 19,771 & 4,795 \\
\hline
\end{tabular}

Table II. Differential proteins.

Participants

Upregulation proteins

Downregulation proteins

Total differentially expressed proteins

Healthy versus respiratory failure

403

421

824

Table III. Proteins identified as upregulated from the isobaric tags for relative and absolute quantification experiment, and an indication of the molecular function and biological processes of these proteins.

\begin{tabular}{|c|c|c|c|c|c|}
\hline No. & Accession & Protein name & Molecular function & Biological process & Max multiple \\
\hline 1 & gil58257696 & KIAA1520 protein & TAP2 binding & $\begin{array}{l}\text { Positive regulation of T-cell } \\
\text { mediated cytotoxicity }\end{array}$ & 34.504 \\
\hline 2 & gil182443 & $\begin{array}{l}5 \text { fibrinogen type B } \\
\text { (AA at 202) }\end{array}$ & $\begin{array}{l}\text { Protein binding, } \\
\text { bridging }\end{array}$ & platelet activation & 27.155 \\
\hline 3 & gil193244949 & $\beta$-globin & Peroxidase activity & $\begin{array}{l}\text { Hydrogen peroxide } \\
\text { catabolic process }\end{array}$ & 26.911 \\
\hline 4 & gil62088878 & Protein 4.1 variant & Calmodulin binding & $\begin{array}{l}\text { Positive regulation } \\
\text { of protein binding }\end{array}$ & 20.145 \\
\hline 5 & gil229959 & $\beta$-globin (fragment) & Peroxidase activity & $\begin{array}{l}\text { Hydrogen peroxide } \\
\text { catabolic process }\end{array}$ & 19.487 \\
\hline 6 & gil284521122 & A- $\gamma$ globin Osilo variant & $\begin{array}{l}\text { Oxygen transporter } \\
\text { activity }\end{array}$ & Oxygen transport & 19.257 \\
\hline 7 & gil28332 & $\begin{array}{l}\text { cDNA FLJ35730 fis, clone } \\
\text { TESTI2003131, highly similar } \\
\text { to } \alpha \text {-1-antichymotrypsin }\end{array}$ & $\begin{array}{l}\text { Serine-type } \\
\text { endopeptidase } \\
\text { inhibitor activity }\end{array}$ & $\begin{array}{l}\text { Negative regulation of } \\
\text { endopeptidase activity }\end{array}$ & 18.890 \\
\hline
\end{tabular}

function, biological process and cellular component associated with each individual protein.

\section{Results}

Identification of proteins. A default significance threshold of $<0.05$ for individual variation was used as the cut-off. There were 19,711 iTRAQ-labeled unique peptides that mapped to a total of 4,795 proteins identified and quantified from PBMCs (Table I). The overlap or commonality of up- and downregulated proteins were subtracted, and 403 proteins were upregulated and 421 proteins were downregulated (Table II). Of these, a difference of a multiple of $\geq 0.5$ points identified 604 , a difference of upregulated $>18$ points included 7 proteins (Table III) and a difference of downregulated $<0.13$ points included 5 proteins (Table IV).

The functional distribution of these proteins is shown in Fig. 1. The GO was used to perform an analysis of 4,795 proteins and to divide the proteins into respective classes based on their molecular function. It found that two of the major groups involved binding (48.71\%) and catalytic activity
(28.68\%) that were apparently changed in RF patients versus healthy controls.

\section{Discussion}

In the past few years, protein quantification has become a critical component of modern MS-based proteomic research $(11,12)$. In addition, numerous quantification strategies have been improved. Almost all of them depend on the incorporation of steady isotopes for subsequent mass spectrometric sorting and relative quantification $(13,14)$.

Through measuring the peak intensities of reporter ions, which are released from iTRAQ-tagged peptides, iTRAQ can compare the protein abundance. iTRAQ could be a potential tool for quantitative proteomic study. In the present study, the proteomics of PBMCs were analyzed in RF patients and healthy controls quantitatively through iTRAQ technology. As a result, 824 proteins, which are involved with different biological functions and cellular locations, were identified, and a proteome database was built for the RF proteome, which to the best of our knowledge has not been reported previously. 
Table IV. Proteins identified as downregulated from the isobaric tags for relative and absolute quantification experiment, and an indication of the molecular function and biological processes of these proteins.

\begin{tabular}{|c|c|c|c|c|c|}
\hline No. & Accession & Protein name & Molecular function & Biological process & Max multiple \\
\hline 1 & gil809369 & $\begin{array}{l}\text { Chain A, crystal structure } \\
\text { of recombinant human } \\
\text { platelet factor } 4\end{array}$ & Heparin binding & $\begin{array}{l}\text { Negative regulation } \\
\text { of angiogenesis }\end{array}$ & 0.091 \\
\hline 2 & gil431896311 & $\begin{array}{l}\text { Myosin regulatory } \\
\text { light polypeptide } 9\end{array}$ & Calcium ion binding & Regulation of cell shape & 0.092 \\
\hline 3 & gil406717976 & MHC class II antigen & Glutamate receptor binding & T-cell costimulation & 0.101 \\
\hline 4 & gil206581665 & $\begin{array}{l}\text { Chain A, human Ll-37 } \\
\text { structure }\end{array}$ & Protein binding & $\begin{array}{l}\text { Protein localization } \\
\text { to microtubule }\end{array}$ & 0.124 \\
\hline 5 & gil122939159 & $\begin{array}{l}\text { Protein-arginine deiminase } \\
\text { type- } 2\end{array}$ & $\begin{array}{l}\text { Protein-arginine } \\
\text { deiminase activity }\end{array}$ & $\begin{array}{l}\text { Peptidyl-citrulline } \\
\text { biosynthetic process } \\
\text { from peptidyl-arginine }\end{array}$ & 0.128 \\
\hline
\end{tabular}

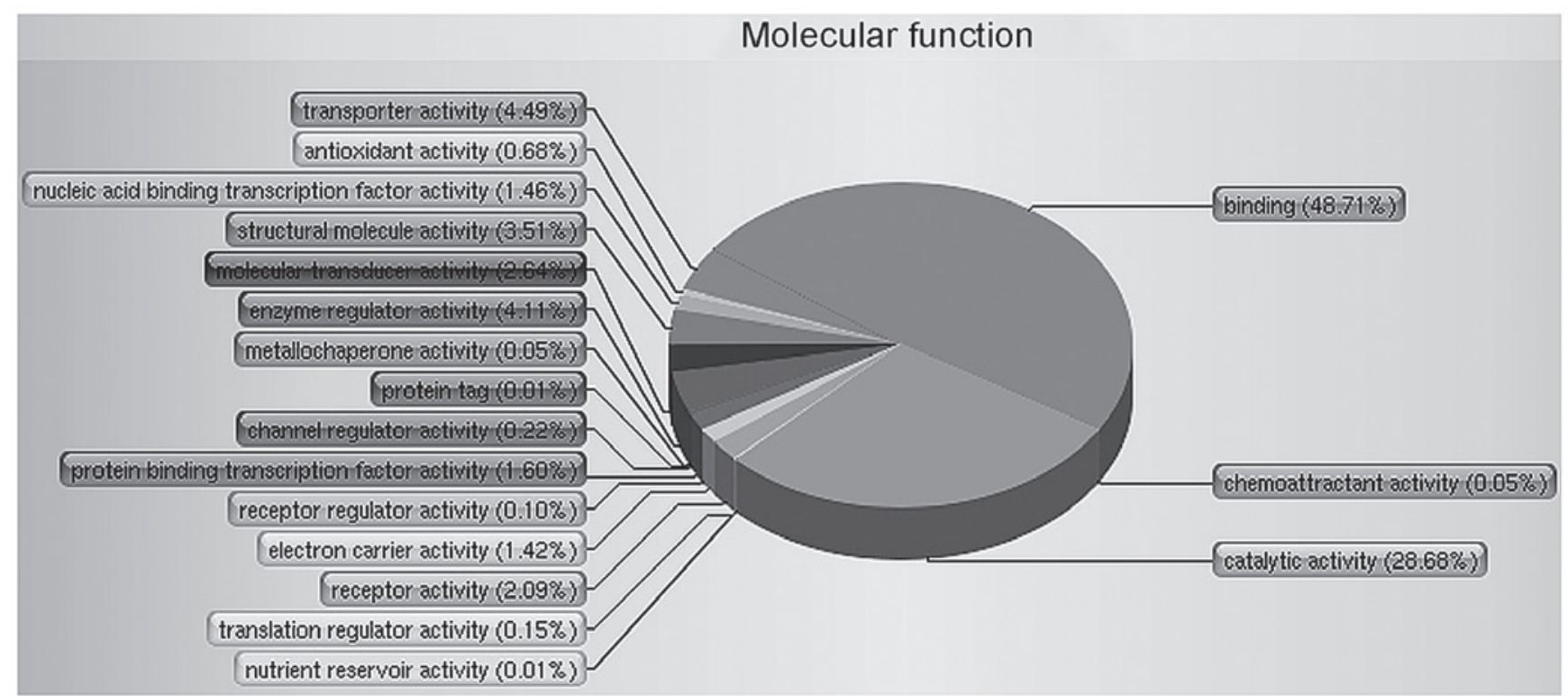

Figure 1. Number of peripheral blood mononuclear cell proteins identified using isobaric tags for relative and absolute quantification reagent and their classification based on molecular function. In total, 4,795 proteins were identified.

The up- and downregulated proteins for the RF and healthy controls are shown in Tables I and II. Among them, there was a significant difference of 4 proteins [upregulated KIAA1520 protein, $\gamma$ fibrinogen type B (AA at 202) and downregulated chain $\mathrm{A}$, crystal structure of recombinant human platelet factor 4 and myosin regulatory light polypeptide 9] in the present iTRAQ study. This provided additional certification that the iTRAQ technique could quantify relative changes in the proteins of PBMC accurately. In addition, the iTRAQ technique has been used for detecting pathological stages or prognosis in certain diseases (12-14). While iTRAQ-based biomarker profiles from tissue have been used for analyzing the pathological stages or prognosis of certain diseases $(15,16)$, the analysis of PBMC in diagnosing the pathological result or progression of RF is only beginning to be explored.

Nagase et al (17) reported the entire sequences of 100 cDNA clones of KIAA1444 to KIAA1543 human genes from cDNA libraries. They found that open reading frames (ORFs) in 10 clones (KIAA1513, KIAA1515, KIAA1520-KIAA1522, KIAA1524, KIAA1525, KIAA1529, KIAA1531 and KIAA1538) carried single or multiple deletions; however, certain ORFs in 23 clones (KIAA1509-KIAA1512, KIAA1514-KIAA1517, KIAA1519-KIAA1521, KIAA1523, KIAA1524, KIAA1526-KIAA1528, KIAA1530 and KIAA1532-KIAA1537) carried single or multiple insertions. The study also reported that 48 gene products have functions correlated with nucleic acid management, cell structure/motility or cell signaling/communication.

The $\gamma \mathrm{A}$ and $\gamma \mathrm{B}$ were the two forms of the $\gamma$ chain of human fibrinogen. The differences between them are only in their carboxyl termini. The protein sequence of $\gamma$-fibrinogen in rats and humans is generally highly conserved (18). The unique $\gamma \mathrm{B}$ sequence, which is coded by human fibrinogen, contained 1 basic residue and 7 acidic (19). Song et al (20) found that 
the levels of plasma viscosity, blood viscosity, hematocrit, fibrinogen and D-dimer were significantly higher in acute exacerbations of chronic obstructive pulmonary disease (AECOPD) patients. The levels of fibrinogen and D-dimer had significantly positively associated with the $\mathrm{PaCO}_{2}$ and negatively associated with the $\mathrm{PaO}$ ) in AECOPD patients combined with RF.

Myosin regulatory light polypeptide 9 is a type of myosin regulatory subunit. It exhibited a critical role in regulating the activities of the smooth muscle and non-muscle cell contractile. In addition, it was involved with cell locomotion, receptor capping and cytokinesis. In lipopolysaccharide-induced lung inflammatory injury, which is the chief cause of the acute respiratory distress syndrome, non-muscle myosin light-chain kinase mediates increased lung vascular endothelial permeability (21).

The functions of certain other novel candidates, such as the chain A, crystal structure of human platelet factor 4 (downregulated in RF), remain to be elucidated. The novel candidates would be more worthy for further investigation.

In the present study, every candidate protein was not discussed in detail. The aim of this preparatory investigation was centered on illustrating the primary comparative protein profiles of RF patients and healthy controls using iTRAQ technology. Furthermore, future studies require the collection of more patient samples to identify the beneficial biomarker candidates of the pathogenesis in RF. In conclusion, the present study showed the potential application of iTRAQ-based quantitative proteomics for the identification of protein changes and potential biomarker candidates in certain diseases.

\section{Acknowledgements}

The authors would like to thank the patients and volunteers who participated in the present study. The study was supported by a grant from the Science and Technology Plan of Shenzhen (no. JCYJ20130401093116730).

\section{References}

1. Roussos C and Koutsoukou A: Respiratory failure. Eur Respir J Suppl 47: 3s-14s, 2003.

2. Roussos $\mathrm{C}$ and Macklem PT: The respiratory muscles. N Engl J Med 307: 786-797, 1982.

3. Burt CC and Arrowsmith JE: Respiratory failure. Surgery 27: 475-479, 2009

4. Chang X, Cui Y, Zong M, Zhao Y, Yan X, Chen Y and Han J: Identification of proteins with increased expression in rheumatoid arthritis synovial tissues. J Rheumatol 36: 872-880, 2009.

5. Gibson DS, Blelock S, Curry J, Finnegan S, Healy A, Scaife C, McAllister C, Pennington S, Dunn M and Rooney M: Comparative analysis of synovial fluid and plasma proteomes in juvenile arthritis - proteomic patterns of joint inflammation in early stage disease. J Proteomics 72: 656-676, 2009.

6. Dai Y, Hu C, Huang Y, Huang H, Liu J and Lv T: A proteomic study of peripheral blood mononuclear cells in systemic lupus erythematosus. Lupus 17: 799-804, 2008.
7. DeSouza LV, Grigull J, Ghanny S, Dubé V, Romaschin AD, Colgan TJ and Siu KW: Endometrial carcinoma biomarker discovery and verification using differentially tagged clinical samples with multidimensional liquid chromatography and tandem mass spectrometry. Mol Cell Proteomics 6: 1170-1182, 2007.

8. Al Badaai Y, DiFalco MR, Tewfik MA and Samaha M: Quantitative proteomics of nasal mucus in chronic sinusitis with nasal polyposis. J Otolaryngol Head Neck Surg 38: 381-389, 2009.

9. Zhou L, Beuerman RW, Chan CM, Zhao SZ, Li XR, Yang H, Tong L, Liu S, Stern ME and Tan D: Identification of tear fluid biomarkers in dry eye syndrome using iTRAQ quantitative proteomics. J Proteome Res 8: 4889-4905, 2009.

10. Hergenroeder G, Redell JB, Moore AN, Dubinsky WP, Funk RT, Crommett J, Clifton GL, Levine R, Valadka A and Dash PK: Identification of serum biomarkers in brain-injured adults: Potential for predicting elevated intracranial pressure. J Neurotrauma 25: 79-93, 2008.

11. Bantscheff M, Schirle M, Sweetman G, Rick J and Kuster B: Quantitative mass spectrometry in proteomics: A critical review. Anal Bioanal Chem 389: 1017-1031, 2007.

12. $\mathrm{Li} \mathrm{X}, \mathrm{Hu} \mathrm{B}$, Ding $\mathrm{J}$ and Chen $\mathrm{H}$ : Rapid characterization of complex viscous samples at molecular levels by neutral desorption extractive electrospray ionization mass spectrometry. Nat Protoc 6: 1010-1025, 2011.

13. Couttas TA, Raftery MJ, Erce MA and Wilkins MR: Monitoring cytoplasmic protein complexes with blue native gel electrophoresis and stable isotope labelling with amino acids in cell culture: Analysis of changes in the 20S proteasome. Electrophoresis 32: 1819-1823, 2011.

14. Albaum SP, Hahne H, Otto A, Haußmann U, Becher D, Poetsch A, Goesmann A and Nattkemper TW: A guide through the computational analysis of isotope-labeled mass spectrometry-based quantitative proteomics data: An application study. Proteome Sci 9: 30, 2011.

15. Hergenroeder G, Redell JB, Moore AN, Dubinsky WP, Funk RT, Crommett J, Clifton GL, Levine R, Valadka A and Dash PK: Identification of serum biomarkers in brain-injured adults: Potential for predicting elevated intracranial pressure. J Neurotrauma 25: 79-93, 2008.

16. Matta A, DeSouza LV, Shukla NK, Gupta SD, Ralhan R and Siu KW: Prognostic significance of head-and-neck cancer biomarkers previously discovered and identified using iTRAQ-labeling and multidimensional liquid chromatography-tandem mass spectrometry. J Proteome Res 7: 2078-2087, 2008.

17. Nagase T, Kikuno R, Ishikawa K, Hirosawa $M$ and Ohara O: Prediction of the coding sequences of unidentified human genes. XVII. The complete sequences of 100 new cDNA clones from brain which code for large proteins in vitro. DNA Res 7: 143-150, 2000.

18. Crabtree GR and Kant JA: Organization of the rat gamma-fibrinogen gene: Alternative mRNA splice patterns produce the gamma A and gamma B (gamma ') chains of fibrinogen. Cell 31: 159-166, 1982.

19. Fornace AJ Jr, Cummings DE, Comeau CM, Kant JA and Crabtree GR: Structure of the human gamma-fibrinogen gene. Alternate mRNA splicing near the 3' end of the gene produces gamma A and gamma B forms of gamma-fibrinogen. J Biol Chem 259: 12826-12830, 1984.

20. Song YJ, Zhou ZH, Liu YK, Rao SM and Huang YJ: Prothrombotic state in senile patients with acute exacerbations of chronic obstructive pulmonary disease combined with respiratory failure. Exp Ther Med 5: 1184-1188, 2013.

21. Xu J, Gao XP, Ramchandran R, Zhao YY, Vogel SM and Malik AB: Nonmuscle myosin light-chain kinase mediates neutrophil transmigration in sepsis-induced lung inflammation by activating beta2 integrins. Nat Immunol 9: 880-886, 2008. 